\title{
Determinants of a smart city in Morocco
}

\author{
Aicha EL ALAOUI, PhD Associate Professor. \\ University of Sultan My Slimane. Faculty Poly-disciplinary. BP: 591, Av. Ibn Khaldoun, CP: \\ 23000, Beni Mellal, Morocco. Tel. (+212) 6635062 11. Email:aicha_elalaoui@yahoo.fr
}

\begin{abstract}
:
Since the beginning of the 21st century, more than half of the world's population lives in urban areas. The 2014 revision of the World Urbanization Prospects notes that the largest urban growth will take place in India, China and Nigeria. In Morocco, population in urban agglomerations of more than 1 million was 22.65 in 2015 , compared to 13.98 in 1960.This situation has considerable consequences for the social, economic and ecological equilibrium of the territories. For that, public and private strategy must respond to the emerging needs of large numbers of citizens coming into cities to realizea real model of a future citywhichneedto be a Smart City. This new conceptmeans 'briefly' a city must (1) use the New Technologies of Information and Communication (NICT) to improvea quality of its citizens' life, (2) integrate all its stakeholders (businesses and government) and citizens in decision-making and (3) dispose of as little waste as possible in order to have a neutral ecological footprint. This communication shows that a smart city is the city well managed, with significant opportunities for economic development and access to basic services, including health care and education, for all people. We concluded that smart city is a democratic and ecological city based on a circular economy, highlighting two factors human development and democracy development which may contribute to the instituting a smart city in Morocco.
\end{abstract}

Keywords: Smart City - Participatory governance - Education and Skills - Human Development - Sustainable development. 


\section{Introduction}

After the industrial revolution in the 18th century, the economic activity changed manner of life, replacing activities associated with land by activities related to the process of production and transformation, such as industry, manufacturing and services.

Since the beginning of the 21th century, more than half of the world's population lives in cities. The 2014 revision of the World Urbanization Prospects notes that the largest urban growth will take place in India, China and Nigeria. The world's urban population increased from 2.3 billion in 1994 to 3.9 billion in 2014 and is projected to grow to 6.3 billion by 2050 , (UN, 2014, p.26). Conversely, the world's rural population remained unchanged between 1994 and 2014 and is projected to decrease in 2050, see figure 1.

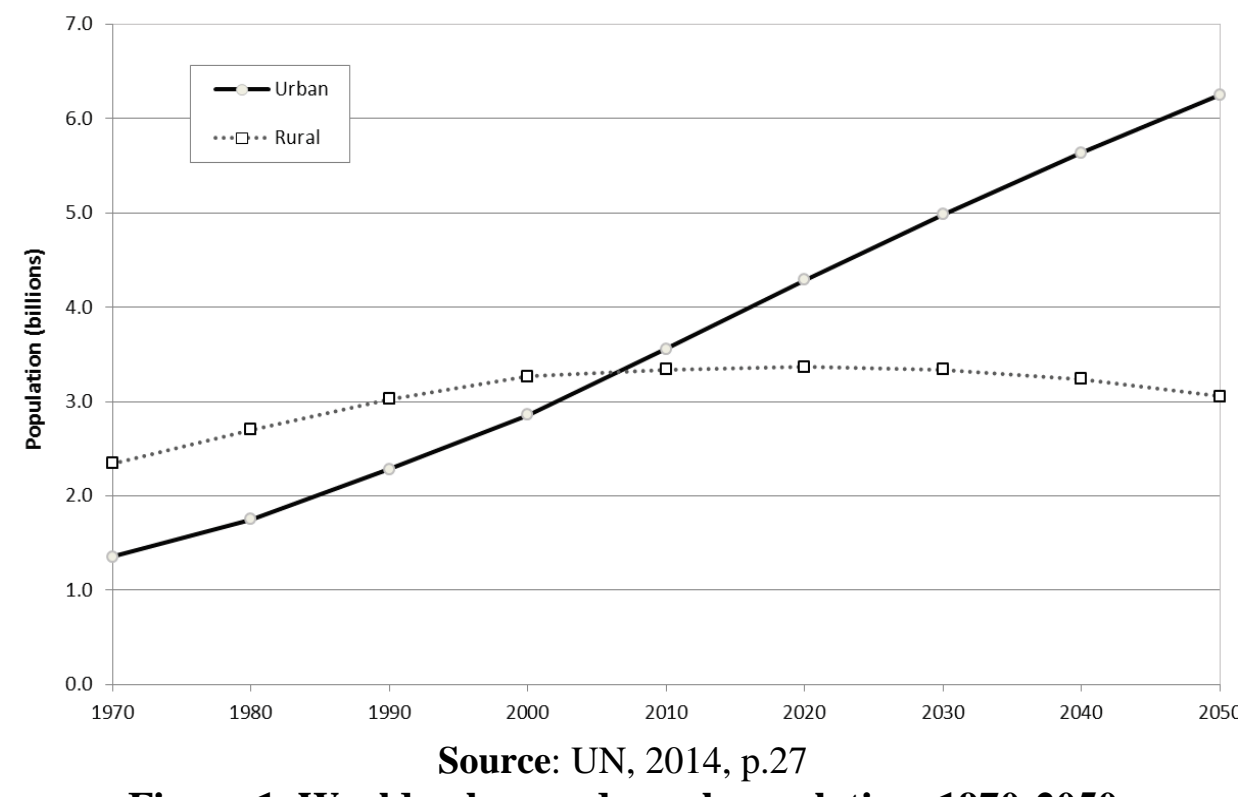

Figure 1. World urban and rural population, 1970-2050

In cities of 10 million inhabitants or more, 10 per cent of the world's population resides in 2014, and that proportion will be expected to increase to almost 14 per cent in 2025 . However, in urban settlements with fewer than 500,000 inhabitants, just 51 per cent of the world's population lived in 2014, and that proportion is expected to fall to 43 per cent in 2025, (UN, 2014, p.27). In Morocco, population in urban agglomerations of more than one million was22.65 in 2015 compared to 13.98 in 1960 according to $U N$ (2016).

Living together in big cities generates several challenges, such as social challenges, food challenges, security challenges, climate challenges and energy challenges.Policy makers must find the right solutions to these challenges to ensure planning, performance and sustainability of territories. Can smart city as a strategy to alleviate the problems generated by the urban population growth and rapid urbanization? What factors are important to be considered in assessing the extent of smart city and can improve the quality of territories and the way of life of the population? Can the smart city will be synonymous an efficiently managed city, an ecological city, a pleasant place to live andwell-connected city? Are we getting smart city to offer the same services to all people in the globe and to talk about smart globe within material barriers as digital/numerical barriers?

In Morocco, this area of study is very limited.But, it is already time to discuss this phenomenon because the smart city is considered as a strategy of long-term. So, this work tries to determine the factors of a smart city in the case of Morocco. It is organized as follows. The second surveys definitions of smart city and its factors. The third section presents the 
problems or challenges of urban population of Morocco. The fourth section presents a model of smart citycan be applied in the case of Morocco because we believe that all cities (small, medium or large) can be smart despite the level of development of the country. The last section concludes.

\section{Defining the smart city and its factors /drivers}

The smart city is a new concept. Tentative of defining and conceptualizing is in progress among manager andresearcher.Boulton, Brunn, and Devriend(2011) confirmed that this concept is used all over the world with different nomenclatures, context and meanings. For example,Nam and Pardo (2011)thought that the smart citywasrepresenting as an organic connection among technology, human and institutional components.

In cooperation with different partners, Giffinger et al. (2007)developed the European Smart City Model which is based in six key fields of urban development: smart economy, smart people, smart governance, smart mobility, smart environment and smart living. These fields are built on the 'smart' combination of endowments and activities of self-decisive, independent and aware citizens. To compare 70 medium-sized European cities, the authors used a method to standardize the values of the different fields named z-transformation: $Z_{i}=$ $\frac{X_{i}-\bar{X}}{S}$. This method transforms "all indicator values into standardized values with an average 0 and a standard deviation 1", (Giffinger et al., 2007, pp.11-14).

Caragliu et al. (2009) believed that city can become smart when investments in human and social capital and traditional (transport) and modern ( $\mathrm{ICT}^{1}$ ) communication infrastructure fuel sustainable economic growth and a high quality of life, with a wise management of natural resources, through participatory governance, (Caragliu et al., 2009, p.50). The authors measure the effect of some relevant variables for urban growth on the GDP of a city, utilized as a proxy for wealth, by means of data sets derived from urban audit ${ }^{2}$. They confirmed existence of a positive correlation between urban welfare and percentage of people employed in the creative sector, the efficiency of the public transport system, the accessibility to services, the level of e-government and, finally, the quality of human capital, (Caragliu et al., 2009, p.58).

Washburn and Sindhu (2010) defined the smart city as "the use of Smart Computing Technologies to make the critical infrastructure components and services of a city -which include city administration, education, healthcare, public safety, real estate, transportation, and utilities- more intelligent, interconnected, and efficient", (Washburn and Sindhu, 2010, p.2). They confirmed that a city makes smart if it uses of Smart Computing ${ }^{3}$ to deliver its core services to the public in a remarkably efficient manner.

Harrison et al. (2010) defined smart city as a city "connecting the physical infrastructure, the $\mathrm{IT}^{4}$ infrastructure, the social infrastructure, and the business infrastructure to leverage the collective intelligence of the city", (Harrison et al., 2010, p.2). They defined smart city as aninstrumented city, intelligentcity andinterconnected city. Instrumented city means "live data"

\footnotetext{
${ }^{1}$ ICT is referred to the information and communications technology.

${ }^{2}$ The Urban Audit entails a collection of comparable statistics and indicators for European cities; it contains data for over 250 indicators across the following domains: Demography, Social aspects, Economic aspects, Civic involvement, Training and education, Environment, Travel and transport, Information society, and Culture and recreation (Caragliu et al., 2009, p.51).

${ }^{3}$ They defined Smart Computing as a new generation of integrated hardware, software, and network technologies that provide technology industry systems with real-time awareness of the real world and advanced analytics to help people make more intelligent decisions about alternatives and actions that will optimize business processes and business balance sheet results, p.2.

${ }^{4} \mathrm{IT}$ is referred to the information technology.
} 
which refers not only systems of sensors and meters that measure some physical parameter such as pressure, flow, and temperature but also software in IT systems that extracts some diagnostic information about an enterprise business process. Interconnected cityimplies that those data areintegrated on a platform and communicated in real-time to the citizens. Intelligent cityrefers to the inclusion of complex analytics, modeling, optimization, and visualization in the operational business processes to ensure that better operational decisions. These characteristics of the city would facilitate the decision-making process especially forbusiness activities.

Lombardi et al. (2011) confirmed that citycan become "smart" if universities and industry support government's investment in the development of such infrastructures. These authors used an advanced Triple-Helix Network Model, including (i)knowledge stock generated by the interplay of universities and industries; (ii)collective 'learning' due to the synergies deriving by the common action of universities and government in searching for efficient public management solutions, and(iii)their institutionalization within on the Market, which form the "contour conditions" that magnify the returns to the original Triple-Helix elements 5 .

Chourabi et al. (2012) confirmed thatthe smart city as a strategy to alleviate the problems generated by the urban population growth and rapid urbanization. They identified eight critical factors of smart city initiatives: management and organization, technology, governance, policy context, people and communities, economy, built infrastructure, and natural environment. They tried to develop an integrative framework to explain the relationships and influences between these factors and smart city initiatives and to suggest directions and agendas for smart city research and outlines practical implications for government professionals. The authors signaled that "each of these factors is important to be considered in assessing the extent of smart city and when examining smart city initiatives", p.2294.

The High Level Group of the European Innovation Partnership for Smart Cities and Communities (2013) highlighted in its report that the Plan of Strategic Implementation for speeding up the transformation of European Cities into "Smart cities" needed establishing strategic partnerships between industry, innovative SMEs, European cities and other stakeholders at local level and across borders in Europe. This group defined smart cities as "systems of people interacting with and using flows of energy, materials, services and financing to catalyze sustainable economic development, resilience, and high quality of life; these flows and interactions become smart through making strategic use of information and communication infrastructure and services in a process of transparent urban planning and management that is responsive to the social and economic needs of society".

Giovannella (2013) mentioned that typical Smart City operational approaches tend to adopt a top-down functionalist model that aims at optimizing, possibly in a standardized manner, the consumption of primary tangible and intangible resources (energy, water, materials, food, etc.) and to save time which is another important resource, usually associated with both money and individual freedom, (Giovannella, 2013, p.2). For that, the author considered "smart citizen" are as "smart consumers" that must be educated to take rational behaviors compatible with the policies promoted by the municipalities aimed at promoting a sustainable economic development.

In its report mapping Smart Cities in the European Union (2014), European parliament defined a smart city as a city seeking to address public issues via $\mathrm{ICT}^{6}$-based solutions on the

\footnotetext{
${ }^{5}$ For more detail see Lombardi et al. (2011), table 2, p.15.

${ }^{6}$ ICT links and strengthens networks of people, businesses, infrastructures, resources, energy and spaces, as well as providing intelligent organisational and governance tools, European Parliament (2014), p.9.
} 
basis of a multi-stakeholder, municipally based partnership, (European parliament, 2014, Box1, p.9). He confirmed the idea of Giffinger et al. (2007) that Smart Cities is "rooted in the creation and connection of human capital, social capital and ICT infrastructure in order to generate greater and more sustainable economic development and a better quality of life. Smart Cities have been further defined along six axes or dimensions: Smart Governance, Smart People, Smart Living, Smart Mobility, Smart Economy and Smart Environment", (European parliament, 2014, p.18).

\section{Challenges linked tourban population explosion in Morocco}

In the last fifty-six years, the Moroccan population has grownat an average rate of $1.9 \%$ per year (figure 2), accompanied by an urban population explosion at rate $2.2 \%$ in 2015 .

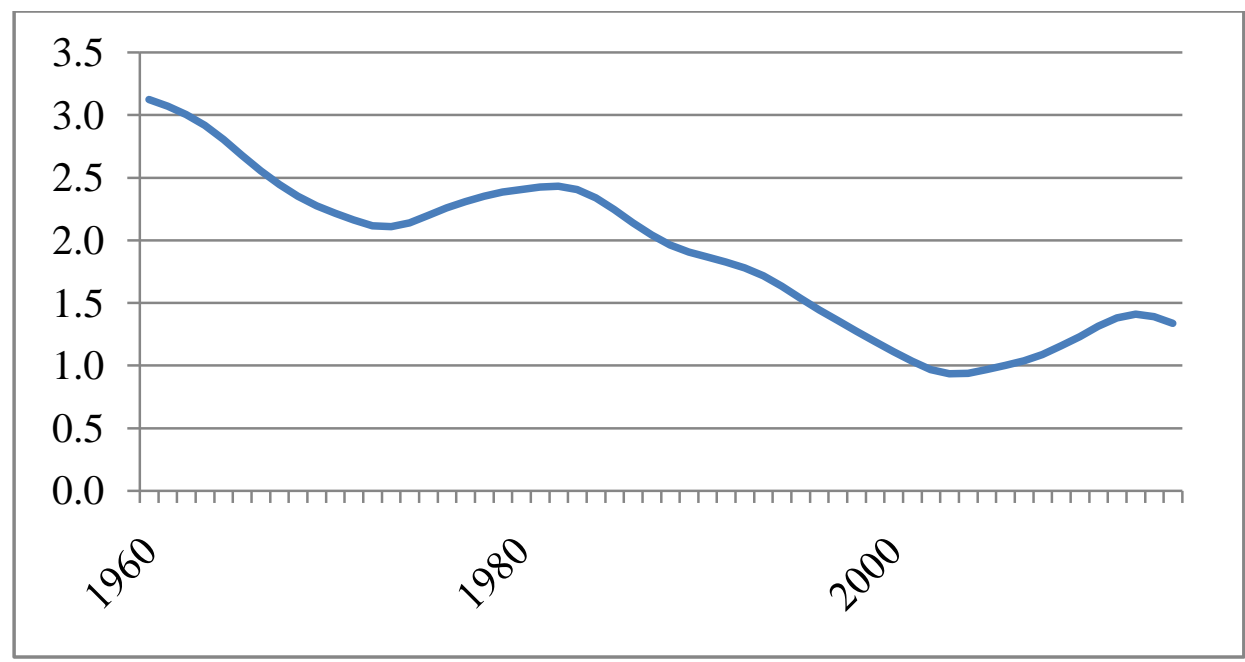

Source: Elaborated according to WDI data, 2016

Figure 2. Moroccan Population growth (annual \%), during 1960-2015

Moroccan population in urban agglomerations of more than one million has grownspeedilyatan average rate of $19.6 \%$ of the total population per year (figure 3 ).

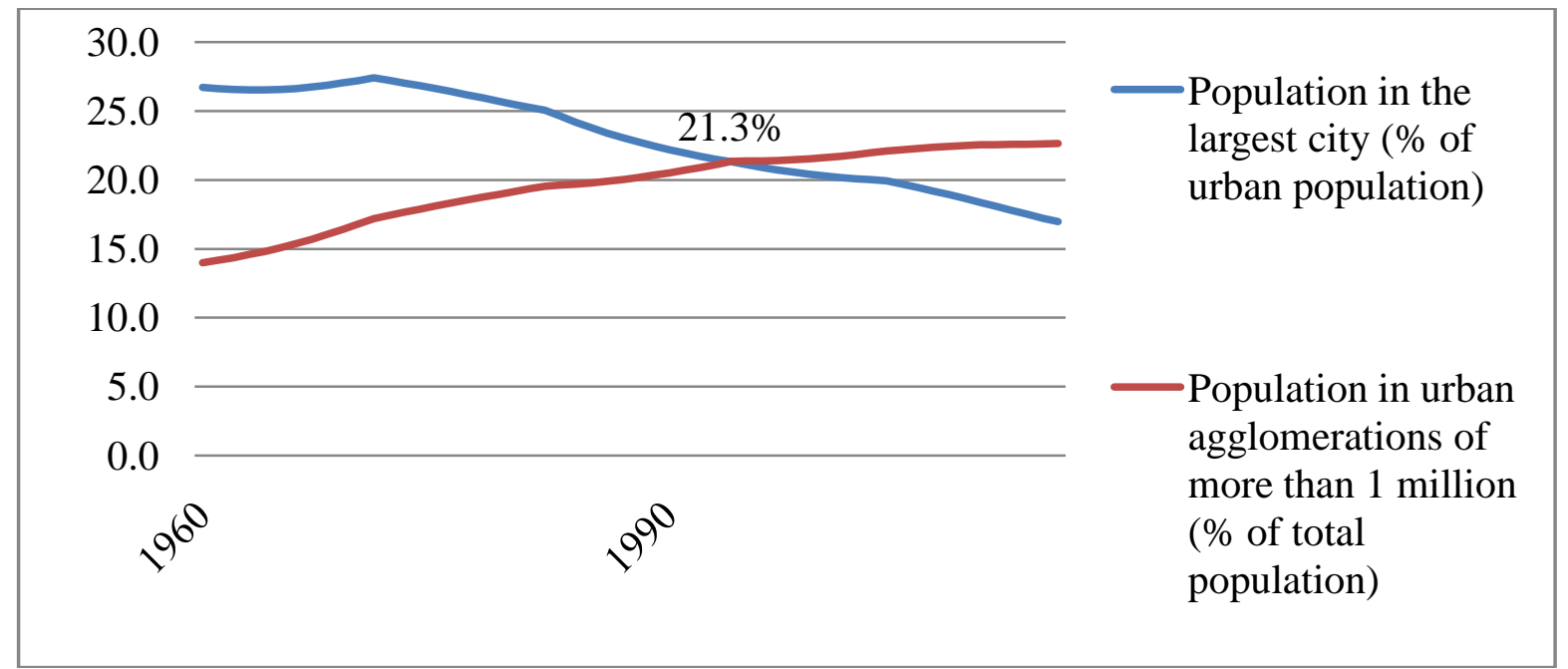

Source: Elaborated according to WDI data, 2016

Figure 3. Urban population \% of the total population, during 1960-2015

Approximately one quarter (23 percent) of the Moroccan population lives in urban areas of $1,000,000$ population or more, which is more important than thatrecorded by India or Nigeria 
(table 1). However, Moroccan population in the largest city (\% of urban population) is on itsdownward trend from $22 \%$ in 1990 to $17 \%$ in 2015.

\begin{tabular}{|c|c|c|c|c|c|c|}
\hline \multirow{2}{*}{$\begin{array}{c}\text { Countries/ } \\
\text { region }\end{array}$} & \multicolumn{2}{|c|}{$\begin{array}{c}\text { Urban } \\
\text { population }\end{array}$} & \multicolumn{2}{c|}{$\begin{array}{c}\text { Population in urban } \\
\text { agglomerations of more } \\
\text { than 1 million }\end{array}$} & \multicolumn{2}{c|}{$\begin{array}{c}\text { Population in the } \\
\text { largest city }\end{array}$} \\
\cline { 2 - 7 } & $\mathbf{1 9 9 0}$ & $\mathbf{2 0 1 5}$ & $\mathbf{1 9 9 0}$ & $\mathbf{2 0 1 5}$ & $\mathbf{1 9 9 0}$ & $\mathbf{2 0 1 5}$ \\
\hline $\mathrm{EAP}^{(\mathrm{a})}$ & $34 \%$ & $57 \%$ & NA & NA & $16 \%$ & $12 \%$ \\
\hline $\mathrm{ECA}^{(\mathrm{b})}$ & $68 \%$ & $71 \%$ & $17 \%$ & $20 \%$ & $15 \%$ & $17 \%$ \\
\hline China $^{\text {Pndia }}$ & $26 \%$ & $56 \%$ & $10 \%$ & $25 \%$ & $3 \%$ & $3 \%$ \\
\hline India & $26 \%$ & $33 \%$ & $11 \%$ & $15 \%$ & $6 \%$ & $6 \%$ \\
\hline MENA & $55 \%$ & $64 \%$ & $24 \%$ & $27 \%$ & $28 \%$ & $26 \%$ \\
\hline Morocco & $48 \%$ & $60 \%$ & $21 \%$ & $23 \%$ & $22 \%$ & $17 \%$ \\
\hline Nigeria & $30 \%$ & $48 \%$ & $12 \%$ & $16 \%$ & $17 \%$ & $15 \%$ \\
\hline World & $43 \%$ & $54 \%$ & $18 \%$ & $23 \%$ & $17 \%$ & $16 \%$ \\
\hline
\end{tabular}

Source: Elaborated according to WDI data, 2016

Table 1. Urban population distribution in \% of the total population

Note:NA signified no-available.

(a). EAP is referred to the East Asia and Pacific;

(b). ECA is referred to the Europe and Central Asia;

(c). MENA is referred to Middle East and North Africa (all income levels).

In 2015, the rural population has difficulty accessing to improve sanitation facilities compared to the urban population (figure 4). The lower situation is recorded in Nigeria and the highest situation is recorded in ECA and MENA.

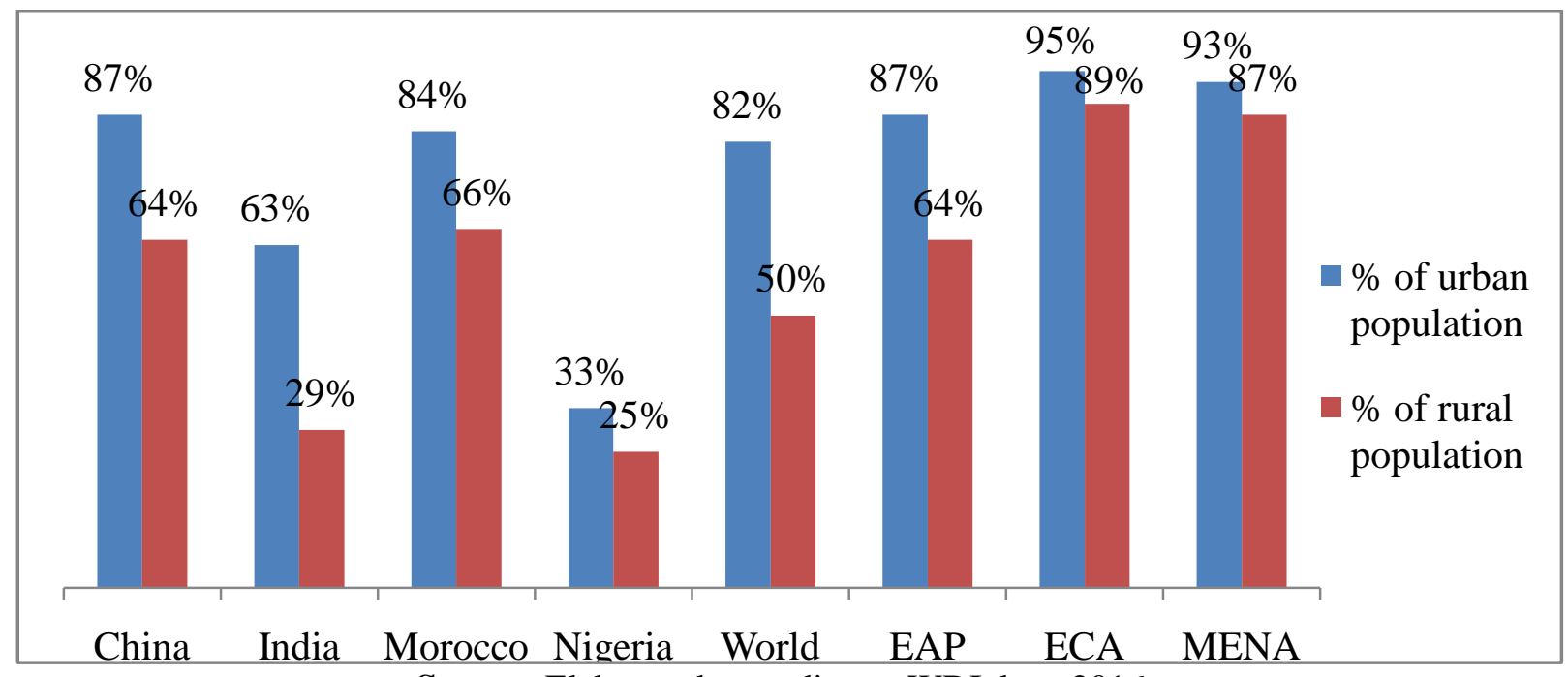

Source: Elaborated according to WDI data, 2016

Figure 4. Access to improved sanitation facilities \% of the total population, 2015

In Morocco, $84 \%$ of the urban population has access to improve sanitation facilities against only $66 \%$ of the rural population. However, all population (rural and urban) has access to the electricity in 2012 according to world development indicator (2016), (figure 4). This situationdoesn't provide any information on quality of life of all citizens and access in all services, especially if we know that Morocco; as other countries of MENA; will be a favorite destination of migration especially migration of people' Sub-Saharan. In its report, the United Nations declared that by 2020 about 60 millions of people will migrate from Sub-Saharan regions to North Africa and Europe. 
For development Index of Information and Communication Technologies (ICT), International Telecommunication Union(ITU)declared in its last report of 2016 that "nearly all countries improved their $\mathrm{IDI}^{7}$ values over the last year, but great disparities continue to exist between more and less connected countries... The gap between the highest and lowest performing countries remained almost unchanged, at 7.76 points in IDI 2016" (ITU, 2016, p.3).According to their IDI rankings, Morocco is at 96th rankamong the 175 countries, with IDI value of 4.60 where it in 83th rank with IDI access value of 6.07 ; 95th rank with IDI use value of 3.40 , and 127 th with IDI skills value of $4.09^{8}$.

\section{Model of Smart City for Morocco}

Intelligent and smart are two concepts differently. Being intelligent is having displaying or characterized by quickness of understanding or good judgment; but being smart is to know exactly how to organize, participate and coordinate all these means. Thatis from intelligent to smart cities. This trajectory meaning main issues:

How can the city continue to develop by limiting its negative externalities, in terms of environmental, fragmentation or agglomeration costs?

What are the opportunities offered by intelligent, synchronized and optimized management of territorial resources through information systems?

How to characterize this evolution in terms of urban ecosystem? What would be the role of citizens and stakeholders (businesses and government) in this new development model?

The urban issue is the most complex and crucial aspect of the sustainable human development problem, such as transport, pollution, demography, integration and so on. For this, the intelligent model in the case of Morocco is in smart city or smart region which design not only the disruptive ways in which people use technology, but also the citizens can, and should, play a role in conceiving, designing, building, maintaining our cities of the future.

The model described in this work has been inspired by the work of many others namely Giffinger et al. (2007) and Cohen (2012).It based on six characteristics: smart economy, smart people, smart governance, smart mobility, smart environment and smart living. Each characteristic is a goal, wherethere are many overall actions and specific actions will be undertaken to help Moroccan citieswill be smart.

These six smart formed a loop where the objective is to realize economic and human development which can improve in turn strengthening of smart city. Thus, there are circular relationships, which it must be started by both smart economy and smart governance (figure 5). These two smart represent the platform to attain other smart, meaning that without 'notably' democracy, equality, transparency and justice in institutions' political and economy of a country, we cannot moving to other smart and realize the overall goal of building of a smart city: economic development and human development of present and future population with durable environmental equilibrium. For that, I started the model with these two smart (smart governance and smart economy) which, as a result, can obtain smart people with knowledge and know-how; and, subsequently, other smart can be established.

In this model, I believe that there is not a linear relationship started by smart governance and smart economy and finished /completed by economic and human development; but there are circular relationships between all those smart.In each period,there are the additional

\footnotetext{
7 IDI is referred to ICT Development Index where ICT presents Information and communication technologies.IDI aggregates quantitative indicators for ICT access, ICT use and ICT skills, (ITU, 2016, annex1, pp.223-230.

${ }^{8}$ For more detail see report of ITU (2016), annex1, pp.223-230.
} 
challengesmore important or complex compared to the previous challenges which will solicit new clever answers/reactions/solutions. So, building a smart city must be in continuous evolvement.

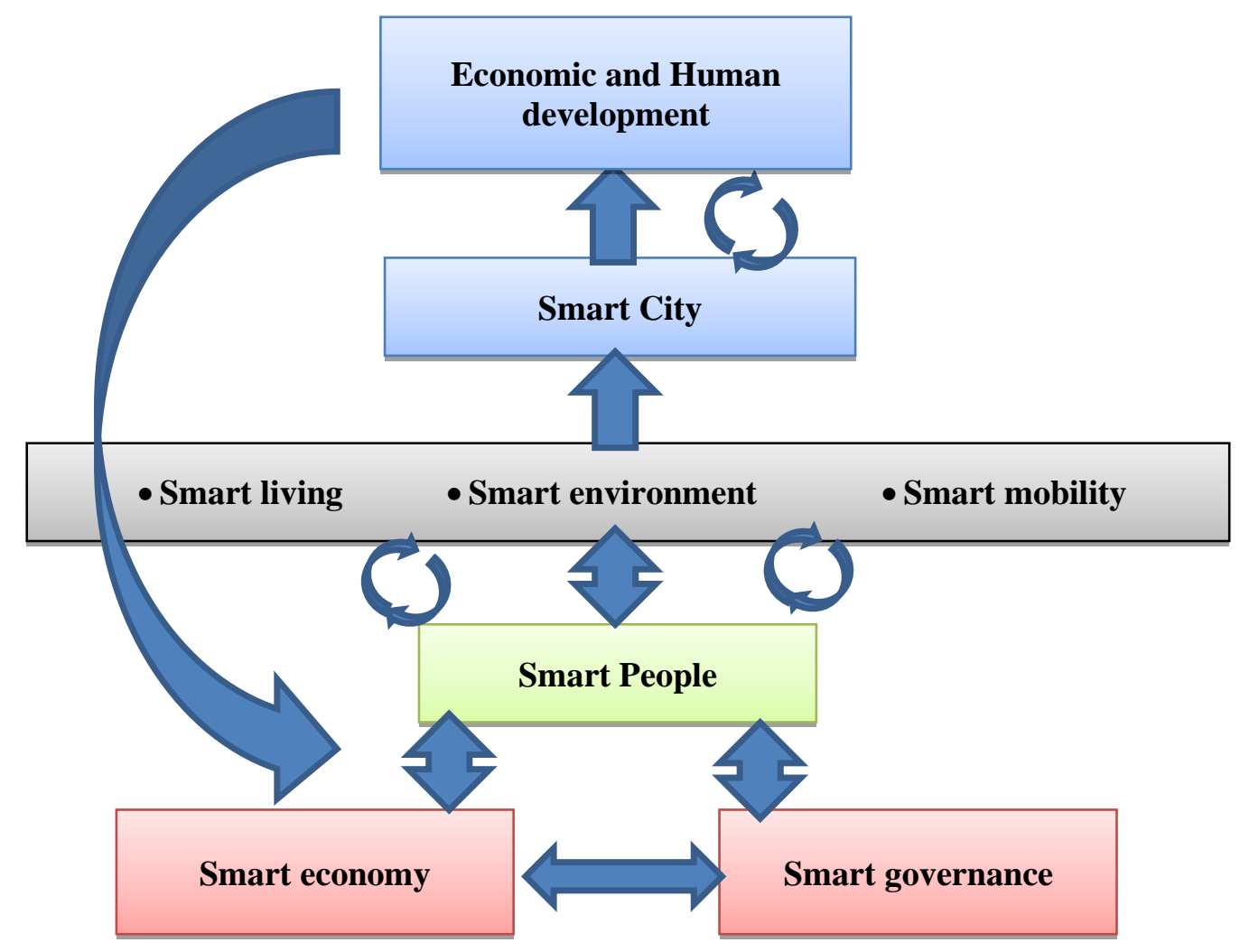

Figure 5. Model of Smart city and relationship between all smarts

\section{Smart economy}

Smart economy is encouraging circular economy (figure 6). The economic activities want to be developed in the smart sectors with smart energy production and consumption (improvements in energy efficiency, reduction of the environmental footprint ...) and smart waste management.

\section{From Linear Economy}

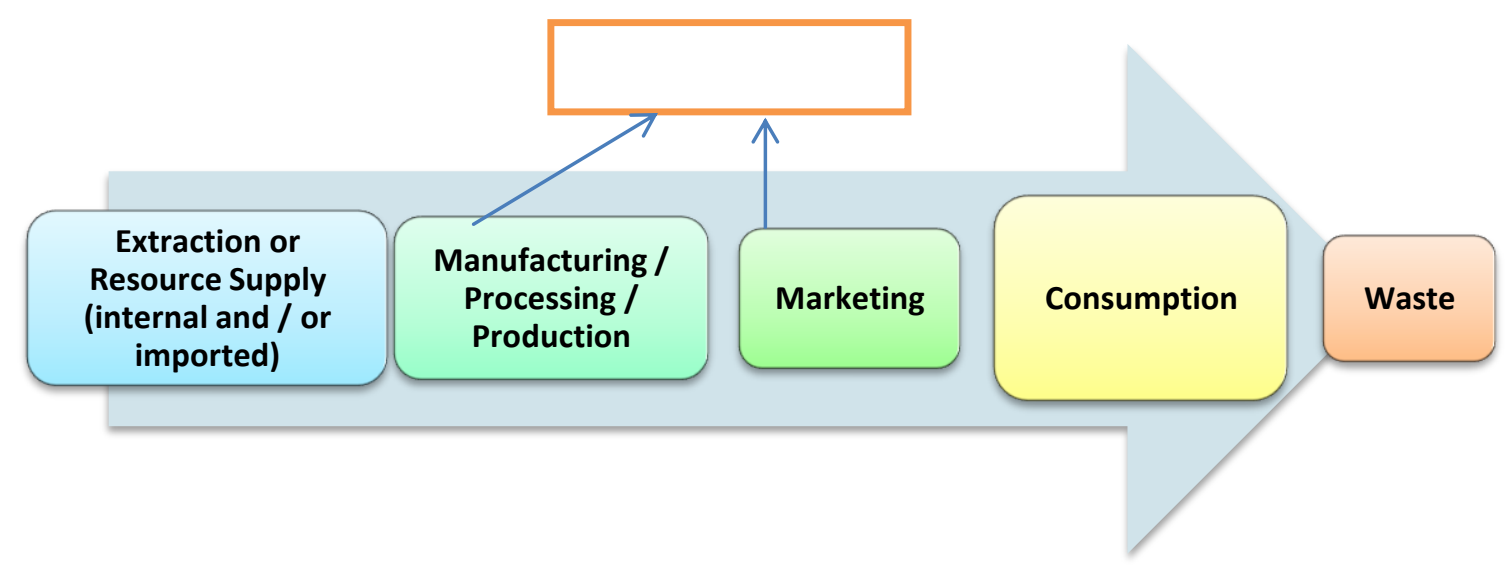

To circular economy 


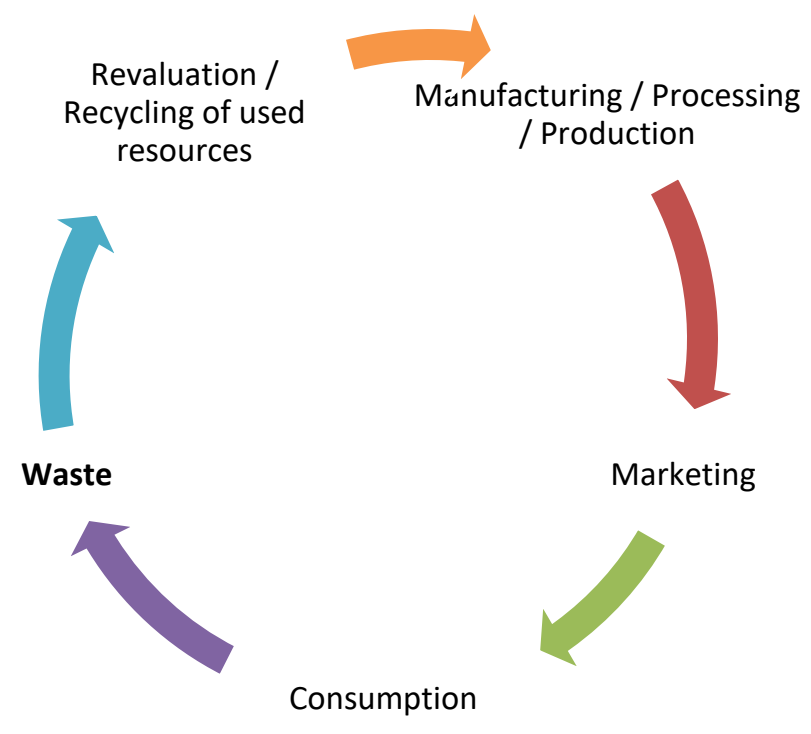

Figure 6. Linear EconomyVs. Circular Economy

\section{Smart governance}

Smart governance is referred to E-democracy, transparency, access and open data, boosting public expenditure on R\&D (research and development) and education, increasing investment onroads and infrastructure, reinforcing social and relational capital such as all social classes should benefit from the success of the high-technology and creative business to prevent social polarization. A smart city community should be taught to learn, adapt and innovate to allow for a long-term sustainability of people capital and well-being (Coe et al. 2001).

\section{Smart people}

Smart people are reinforcing educationand skills. The role of human capital has a positive correlation between growth of the city and the share of highly educated and skilled workforce (Berry and Glaeser, 2005; El Alaoui, 2016). The higher education levels lead to a better environment for new enterprises, creating new knowledge, jobs and business opportunities. However, concentration of human capital in a few cities may lead to increasing economic inequality between "smart" and the rest of cities (Glaeser and Berry, 2006).

\section{Smart living}

Smart living meansthe best conditions of life (security and quality of life), meaning living with healthy people and healthy buildings in the best conditions. So, city utility infrastructure (water/electricity/heating network, lighting, waste disposal...) and smart sensor network (internet foreverything project)...

\section{Smart environment}

Smart environment is efficiency and sustainability, ecologically sustainable enterprises, renewable energy production, urban tooling and pollution control. It is related to the circular economy.

\section{Smart mobility}

Smart mobility is reinforcing logistics and infrastructures, such as public transport, bicycling and bike sharing, introduction of hybrid and compressed natural gas (CNG) powered buses and vehicles to reduce emissions (CNG)-powered buses and electrical vehicles (EVs) solutions, reduction and best management solutions of traffic,... 


\section{Conclusion}

The concept of smart city is implementedin many cities,such as Barcelona, Berlin, Hamburg, London and Vienna.In Morocco,it is far from realization because the six indicators/factors will require huge investments and significant adaptation of business. Building a smart city in Morocco is a long-term strategy. In medium-term, it must be focused improving democracy, education and knowledge and moving towards a circular economy centered on human developmentand ecological equilibrium.

Smart city is a democratic and ecological city based on a circular economy, highlighting two factors human development and democracy development which may contribute to the instituting a smart city in Morocco.

\section{References}

Attour, A., \&Rallet, A. (2014). "Le rôle des territoires dans le développement des systèmes trans-sectoriels d'innovation locaux : le cas des smartcities". Innovations, 1(43), 253-279.

Boulton, A., Brunn, S.D., \&Devriendt, L. (2011)."Cyberinfrastructures and "smart" world cities: Physical, human, and soft infrastructures". In Taylor, P., Derudder, B., Hoyler, M., \&Witlox, F. (Eds.), International Handbook of Globalization and World Cities. Cheltenham, UK: Edward Elgar. Available from http://www.neogeographies.com/documents/cyberinfrastructure_smart_world_cities.pdf.

Caragliu, A, Del Bo, C. \&Nijkamp, P. (2009). "Smart cities in Europe". Series Research Memoranda 0048.

Chourabi, H., Nam, T., Walker, S. Gil-GarciaJ. Ramon., Mellouli, S., Nahon, K., Pardo Theresa A., Scholl H.J., (2012). "Understanding Smart Cities: An Integrative Framework". 45th Hawaii International Conference on System Sciences. 978-0-7695-4525-7/12. IEEE DOI 10.1109/HICSS.2012.615.

Coe, A., Paquet, G., Roy, J. (2001)."E-Governance and Smart Communities: A Social Learning Challenge". Social Science Computer Review, 19, p. 80-93.

Cohen, B. (2012). "What Exactly Is A Smart City? "Co.Exist. http://www.fastcoexist.com/ 1680538/what-exactly-is-a-smart-city

El Alaoui, A. (2016). "What kind of women's education that affects economic growth?". The Journal of Quality in Education. N7, 2016, pp.35-47.

European Parliament, report (2014). "Mapping Smart Cities in the EU". Directorate general for internal policies policy department A: Economic and scientific policy. IP/A/ITRE/ST/2013-02. PE 507.480. http://www.europarl.europa.eu/studies

Giffinger R. et al (2007). "Smart Cities: Ranking of European Medium-Sized Cities", Vienna, Austria: Centre of Regional Science (SRF), Vienna University of Technology. www.smartcities.eu/download/smart_cities_final_report.pdf

Giovannella C. (2013)."Territorial Smartness and Emergent Behaviors in ICSCS". IEEE publisher, pp. 170-176

Glaeser, E.L. , Berry, C.R. (2006). "Why Are Smart Places Getting Smarter? ".Taubman Center Policy Brief 2006 - 2, Cambridge, MA: John F. Kennedy School of Government.

Harrison, C., Eckman, B., Hamilton, R., Hartswick, P., Kalagnanam, J., Paraszczak, J., and Williams, P. (2010)."Foundations for Smarter Cities". In IBM Journal of Research and Development, 54(4), pp1-16.

International Telecommunication Union, ITU, (2016). "Measuring the Information Society Report".PP.1-274.http://www.itu.int/en/ITU-D/Statistics/Documents/publications/misr 2016/MISR2016-w4.pdf 
Lombardi P., Giordano S., Caragliu A., Del Bo C., Deakin M., Nijkamp P., Kourtit K. (2011)."An Advanced Triple-Helix Network Model for SmartCities performance". Research Memorandum 2011-45.

Nam, T. and Pardo, T.A. (2011). "Conceptualizing Smart City with Dimensions of Technology, People, and Institutions". The Proceedings of the 12th Annual International Conference on Digital Government Research, pp. 282- 291. https://intaaivn.org/images/cc/Urbanism/ background\%20documents/dgo_2011_smartcity.pdf

Smart City and Communities, (2013). "European Innovation Partnership on Smart Cities and Communities: Strategic Implementation Plan". https://eu-smartcities.eu/sites/all/files/ SIP.pdf

United Nations, Department of Economic and Social Affairs Population Division (2014)."The World Population Situation in 2014: A Concise Report". NY, ST/ESA/SER.A/354. Pp.138.

Washburn, D. and Sindhu, U. (2010). "Helping CIOs Understand "Smart City" Initiatives", for CIOs. Forrester Research, Inc. 